\title{
PERBAIKAN MODEL TRAFIK JAM SIBUK MELAUI PENDEKATAN GOS PADA JARINGAN PITA LEBAR WIRELINE SPEEDY
}

\author{
Ivany Sarief \\ Program Studi Teknik Elektro \\ Universitas Sangga Buana YPKP \\ ivansarief@gmail.com
}

\begin{abstract}
ABSTRAK
Meningkatnya permintaan layanan internet bagi penyedia layanan jaringan pita lebar seperti speedy membutuhkan peningkatan fasilitas jaringan seperti perangkat sistem, teknologi dan coverage. secara kuantitas perlu dianalisis perbaikan model trafik terkait dengan kondisi kemampuan jaringan dalam memfasilitasi kapasitas daya tampung terhadap meningkatnya permintaan pelanggan agar tidak mengakibatkan jaringan menjadi terganggu. Indikasinya terlihat ketika jaringan sedang melayani pelanggan saat jam sibuk secara bersamaan tanpa adanya pemblokiran. Berdasarkan perbaikan model trafiknya dihasilkan perhitungan probabilitas pemblokiran panggilan saat jam sibuk sebesar $15,9 \%$ untuk jumlah panggilan sebanyak 135 dengan kebutuhan perbaikan kapasitas jaringannya sebesar 5,33 Mbps.
\end{abstract}

Kata Kunci: Jaringan Speedy, Grade of Service, Jam Sibuk, Probabilitas Pemblokiran, Kapasitas Jaringan, Internet

\section{PENDAHULUAN}

Meningkatnya kebutuhan dan permintaan akan layanan internet saat ini terutama untuk layanan jaringan speedy menjadikan meningkatnya penggunaan fasilitas jaringan antara lain perangkat sistem, teknologi dan luas cakupan jaringan. Dari sisi kuantitas dirasakan cukup memberikan prospek bisnis yang sangat baik, namun dampak lainnya adalah semakin banyak masalah yang berkaitan dengan jaringan ini seperti kondisi kemampuan jaringan yang tidak mampu menampung banyaknya perrmintaan pelanggan. Hal ini mengakibatkan layanan menjadi terganggu yang tentunya berdampak merugikan pelanggan itu sendiri. Salah satu indikasinya ketika jaringan speedy yang tersedia tersebut pada saat jam sibuk mampu melayani permintaan secara bersamaan tanpa adanya proses pemblokiran sehingga kemampuan kinerja jaringan dapat dilihat dari kondisi ini. Upaya perbaikan jaringan speedy dilakukan ketika semua jaringan digunakan secara bersamaan waktu puncak beban jaringan terjadi yaitu saat kondisi jam sibuk terjadi yang secara langsung berdampak pada probabilitas meningkatnya penolakan permintaan layanan atau GOS pada suatu trafik jaringan pita lebar speedy. Karena itu diperlukan suatu pemodelan terkait dengan langkah-langkah perbaikan manajemen trafik jaringan.

Metode yang diterapkan pada tahapan pemodelan ini adalah melakukan observasi terhadap berbagai perubahan kondisi jaringan dalam rentang waktu tertentu melalui perkiraan waktu terjadinya situasi jam sibuk dengan menghitung tingkat persentase Grade Of service dengan mengamati perubahan intensitas trafik, holding time dan distribusi probabilitas.

\subsection{Jaringan Pita Lebar Speedy}

Prinsip dasar jaringan speedy adalah dari Pengoptimalan Kinerja Jaringan Kabel Tembaga yang memiliki frekuensi transmisinya masih terbatas $<4 \mathrm{KHz}$ hanya untuk informasi suara dengan jarak $5 \mathrm{~s} / \mathrm{d} 10 \mathrm{~km}$. Sebagian besar hanya digunakan untuk komunikasi suara. frekuensi 4 $\mathrm{KHz}$ yang digunakan untuk Layanan Voice saja adalah frekuensi tanpa modulasi, sehingga masih ada "ruang" untuk meningkatkan kapasitas dengan menggunakan teknik modulasi tertentu. Sehingga untuk mengoptimalkan jaringan akses 
tembaga eksisting diperlukan Teknologi berbasis ADSL (Asymeric Digital Subscribe Line). Prinsip jaringannya ditunjukan seperti gambar berikut ini:

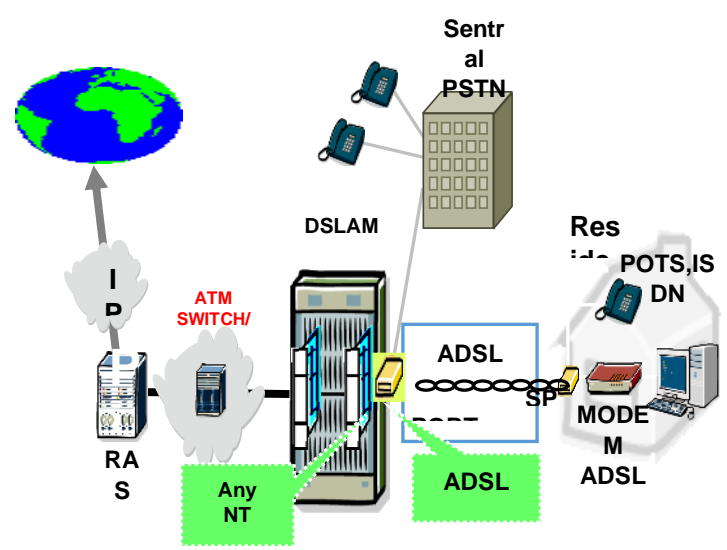

Gambar 1 Arsitektur Jaringan Speedy

\subsection{Model Trafik Jam Sibuk}

Dasar pemodelan sebuah trafik komunikasi dalam sebuah jaringan pita lebar merujuk pada keterkaitan beberapa parameter dalam membangun suatu hubungan antara panggilan yang masuk ke sistem terhadap jumlah panggilan yang mampu diproses oleh sistem tersebut dimana parameter itu antara lain kapasitas sistem, beban trafik dan kualitas pelayanan. Ketiga parameter ini mampu dijadikan dasar mengambil keputusan terhadap penentuan kualitas kinerja dan model yang digunakan pada suatu konfigurasi jaringan. Sedangkan komponen-komponen utama yang diperlukan untuk mendukung keputusan ini antara lain intensitas trafik dan kemungkinan terjadinya kemungkinan pemblokiran yang keterkaitan dengan analisis GOS (grade of service) terhadap kapasitas sistem. Intensitas trafik sendiri menyatakan jumlah rata-rata saluran yang diduduki secara bersamaan dalam waktu tertentu dan dinyatakan sebesar :

$$
Y(T)=\frac{1}{T} \cdot \int_{0}^{T} n(t) \mathrm{d} t
$$

Sedangkan kemungkinan terjadinya pemblokiran pada sistem dinyatakan melalui pendekatan persamaan:

$$
G O S=\frac{A^{n} / n^{!}}{1+A+\left(\frac{A^{2}}{2^{!}}\right)+\cdots\left(\frac{A^{n}}{n^{!}}\right)}
$$

Pemodelan trafik pada situasi jam sibuk sendiri secara khusus dapat dinyatakan dalam kurun priode harian agar diperoleh variasi trafik secara umum untuk selanjutnya dapat menentukan kualitas jaringan apakah perlu adanya perbaikan atau tidak melalui analisis tiga pendekatan yaitu average daily peak hour (ADPH), time consistent busy hour (TCBH) dan fixed daily measurement hour (FDMH).

\subsection{Koneksitas Jaringan Pita Lebar Speedy}

Untuk melakukan koneksi internet dengan SPEEDY tidaklah sulit, kita dapat mengkonfigurasinya sendiri. Ada pun perangkat yang kita perlukan adalah Line telepon, Modem ADSL, Spliter dan Username dan password Speedy. Kemudian untuk mengkonfigurasi PC kita agar dapat terkoneksi ke internet dengan memakai speedy diperlukan beberapa langkah, di antaranya :

- Pengecekan tipe sambungan telepon rumah (tungal, paralel, atau PABX)

- Pemisahan jalur voice dan data dengan menggunakan spliter

- Koneksikan modem ADSL dengan PC dan mulai mengkonfigurasinya

- Membuat koneksi untuk Speedy pada PC

- Test koneksi

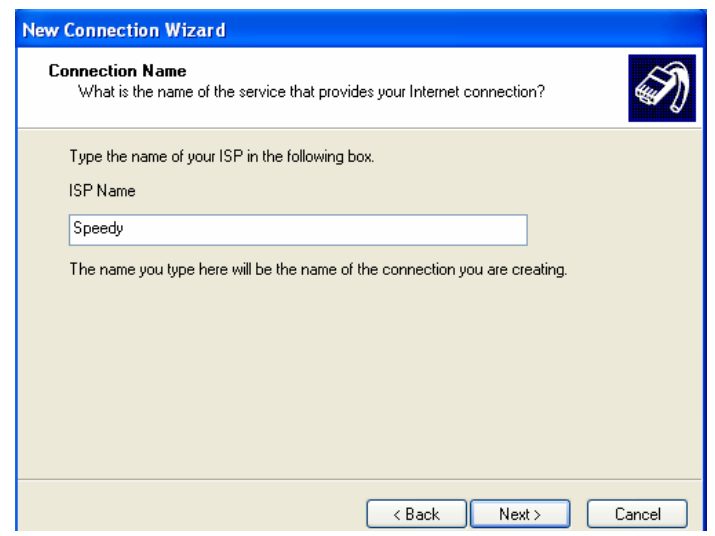

(a) 


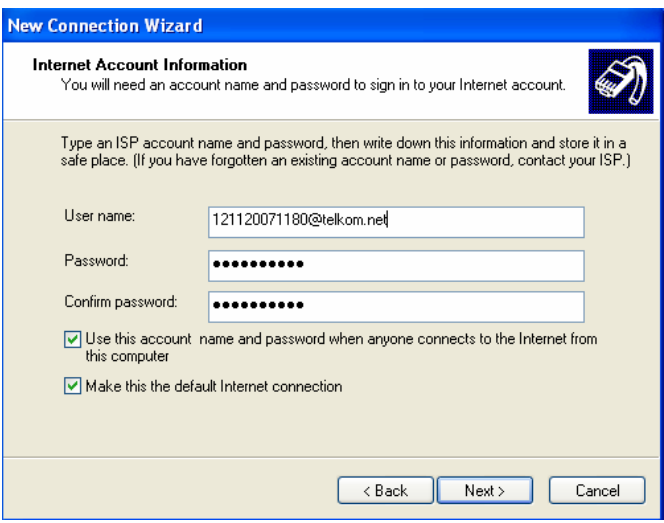

(b)

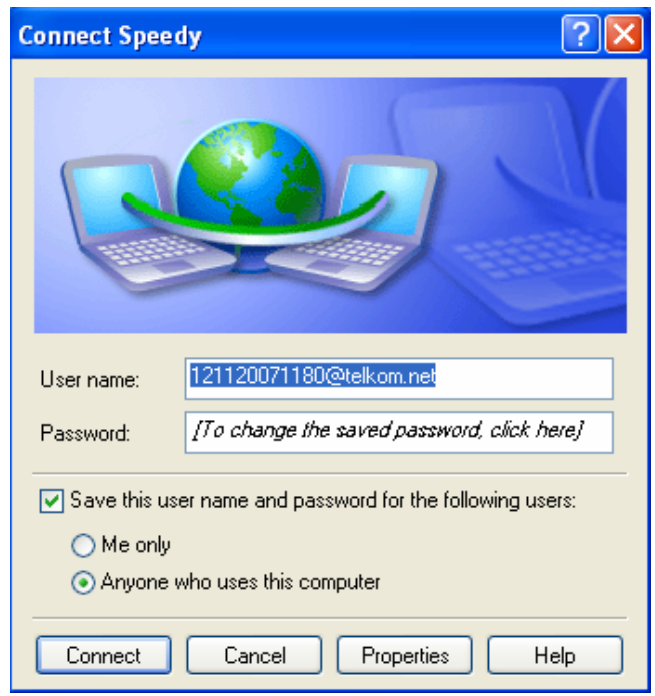

(c)

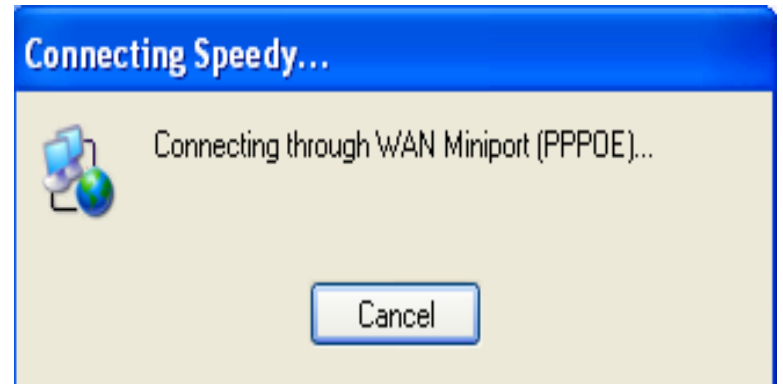

(e)

Gambar 2. Tahapan Instalasi Koneksitas Speedy

\section{METEDOLOGI}

Metoda analisis perhitungan untuk mengidentifikasi kondisi jaringan speedy pada keadaan jam sibuk dihitung dan dianalisis per hari dengan tujuan memperkirakan kinerja jaringan speedy secara keseluruhan. Adapun metoda perhitungan tersebut antara lain:

\section{a. Metoda Time Consistent Busy Hour}

Perhitungan jam sibuk dengan metoda ini didasarkan pada keadaan jam sibuk dalam sehari selama 7 hari dengan menentukan nilai rata-rata trafik tertinggi. Trafik ini diukur pada hari kerja, dengan mengabaikan hari libur dan hari abnormal (keadaan ideal) dimana pendekatannya dinyatakan oleh:

$$
\begin{aligned}
& \text { Trafik rata - rata Jam Sibuk } \\
& \qquad=\frac{\text { trafik terting gi per hari }}{\text { jumlah hari yang di ukur }}
\end{aligned}
$$

\section{b. Metoda Bouncing Busy Hour}

Metoda perhitungan Bouncing Busy Hour ini lebih menitik beratkan hanya pada trafik puncak yang diperhitungan per 1 hari, per 1 minggu, per 1 bulan dan per 1 tahun. Tetapi faktanya kalkulaso dilakukan berdasarkan kondisi trafik puncak per 1 hari untuk data yang diambil selama 1 minggu ( 7 hari) dimana besarnya dinyatakan oleh:

$$
\begin{aligned}
& \text { Trafik rata - rata Jam Sibuk } \\
& \qquad=\frac{\sum_{n=1}^{N=7}\{\text { Trafik terting hari } k e-n\}}{\text { jumlah hari yang di ukur }}
\end{aligned}
$$

Perbaikan sistem jaringan speedy senyatanya dapat diperkirakan bentuknya melalui pendekatan perhitungan berdasarkan probabilitas. Hal ini berkaitan dengan 3 komponen utama yang menjadikan kualitas kinerja jaringan dapat dianalisis yaitu kapasitas jaringan, beban trafik jaringan dan GOS. Dalam penelitian ini penekanan perbaikan trafik jaringan lebih terfokus pada parameter GOS terutama di dalamnya terkait dengan perkiraan probabilitas pemblokiran atau blocking process. Metode yang akan digunakan merupakan sebuah pendekatan distribusi Poisson sebesar :

$$
P(n)=\frac{A^{n}}{n !} x e^{-A}
$$


Sedangkan tinjauan kapasitas jaringan speedy dapat dukur berdasarkan formula Shannon yang menentukan perkiraan kapasitas kanal transmisi yaitu sebesar:

$C=B \log _{2}(1+S N R)$

(4)

Menurut Shannon Signal to Noise Ratio (SNR) sangatlah penting dalam transmsi sinyal digital data karena mampu menyusun batas atas terhadap rate data yang mampu dicapai selain lebar pita transmisi yang mengikutinya.

\section{HASIL DAN PEMBAHASAN}

Pengukuran model perbaikan pada jaringan ketika jam sibuk dilakukan dengan mengambil beberapa sampel data berdasrkan spesifikasi katagori antara lain:

1. Data diambil selama satu bulan yaitu sampel data di bulan April 2017

2. Perhitungan dilakukan untuk setiap data per minggu dalam bulan April 2017

3. Analisis perbaikan jaringan dilakukan menggunakan pendekatan perhitungan GOS mengacu pada sisi nilai blocking process

Adapun data hasil pengamatan dan pengukuran selama satu bulan dengan dengan mengacu pada data trafik yang diamati setiap minggunya ditunjukan pada tabel 1 sampai dengan tabel 4 berikut ini:

Tabel 1. Data hasil minggu ke-1

\begin{tabular}{|c|c|c|c|c|c|c|c|c|}
\hline \multirow{2}{*}{ WAKTU } & \multicolumn{7}{|c|}{ JUMLAH PANGGILAN } & \multicolumn{2}{c|}{$\begin{array}{c}\text { Rata-rata } \\
\text { Lama } \\
\text { panggilan } \\
\text { (Menit) }\end{array}$} & SNR \\
\hline $07.00-09.00$ & $\mathbf{S}$ & $\mathbf{S}$ & $\mathbf{R}$ & $\mathbf{K}$ & $\mathbf{J}$ & $\mathbf{S}$ & \pm 10 & 38 \\
\hline $09.00-11.00$ & 0 & 0 & 0 & 2 & 1 & 0 & \pm 10 & 42 \\
\hline $11.00-13.00$ & 0 & 0 & 0 & 0 & 3 & 1 & \pm 10 & 40 \\
\hline $13.00-15.00$ & 0 & 1 & 1 & 0 & 2 & 2 & \pm 10 & 32 \\
\hline $15.00-17.00$ & 0 & 0 & 1 & 0 & 3 & 1 & \pm 10 & 38 \\
\hline $17.00-19.00$ & 0 & 0 & 0 & 0 & 1 & 0 & \pm 10 & 42 \\
\hline $19.00-21.00$ & 0 & 0 & 1 & 0 & 1 & 2 & \pm 10 & 40 \\
\hline
\end{tabular}

Tabel 2. Data hasil minggu ke-2

\begin{tabular}{|c|c|c|c|c|c|c|c|c|}
\hline \multirow[b]{2}{*}{ WAKTU } & \multicolumn{6}{|c|}{ JUMLAH PANGGILAN } & \multirow{2}{*}{$\begin{array}{l}\text { Rata-rata } \\
\text { Lama } \\
\text { panggilan } \\
\text { (Menit) }\end{array}$} & \multirow[b]{2}{*}{ SNR } \\
\hline & $\mathbf{S}$ & $\mathbf{S}$ & $\mathbf{R}$ & $\mathbf{K}$ & $\mathbf{J}$ & $\mathbf{S}$ & & \\
\hline $\begin{array}{c}07.00- \\
09.00\end{array}$ & 1 & 0 & 1 & 0 & 2 & 1 & \pm 10 & 38 \\
\hline $\begin{array}{c}09.00- \\
11.00\end{array}$ & 0 & 0 & 0 & 2 & 1 & 0 & \pm 10 & 42 \\
\hline $\begin{array}{c}11.00- \\
13.00\end{array}$ & 0 & 0 & 0 & 0 & 3 & 1 & \pm 10 & 40 \\
\hline $\begin{array}{c}13.00- \\
15.00\end{array}$ & 0 & 1 & 1 & 0 & 2 & 2 & \pm 10 & 32 \\
\hline $\begin{array}{c}15.00- \\
17.00\end{array}$ & 0 & 0 & 1 & 0 & 3 & 1 & \pm 10 & 38 \\
\hline $\begin{array}{c}17.00- \\
19.00\end{array}$ & 0 & 0 & 0 & 0 & 1 & 0 & \pm 10 & 42 \\
\hline $\begin{array}{l}19.00- \\
21.00\end{array}$ & 0 & 0 & 1 & 0 & 1 & 2 & \pm 10 & 40 \\
\hline
\end{tabular}


Tabel 3.

Data hasil minggu ke-3

\begin{tabular}{|c|c|c|c|c|c|c|c|c|}
\hline \multirow{2}{*}{ WAKTU } & \multicolumn{6}{|c|}{ JUMLAH PANGGILAN } & \multirow{2}{*}{$\begin{array}{c}\text { Rata-rata } \\
\text { Lama panggilan } \\
\text { (Menit) }\end{array}$} & \multirow{2}{*}{ SNR } \\
\hline & $\mathbf{S}$ & $\mathbf{S}$ & $\mathbf{R}$ & $\mathbf{K}$ & $\mathbf{J}$ & $\mathbf{S}$ & & \\
\hline $07.00-09.00$ & 0 & 0 & 4 & 1 & 0 & 1 & \pm 10 & 36 \\
\hline 09.00-11.00 & 4 & 1 & 3 & 0 & 2 & 3 & \pm 10 & 30 \\
\hline $11.00-13.00$ & 9 & 3 & 0 & 2 & 0 & 8 & \pm 10 & 28 \\
\hline $13.00-15.00$ & 2 & 2 & 0 & 3 & 1 & 5 & \pm 10 & 32 \\
\hline $15.00-17.00$ & 2 & 1 & 2 & 3 & 2 & 8 & \pm 10 & 28 \\
\hline $17.00-19.00$ & 0 & 0 & 7 & 1 & 0 & 6 & \pm 10 & 28 \\
\hline $19.00-21.00$ & 0 & 0 & 5 & 1 & 2 & 4 & \pm 10 & 30 \\
\hline
\end{tabular}

Tabel 4. Data hasil minggu ke-4

\begin{tabular}{|c|c|c|c|c|c|c|c|c|}
\hline \multirow[b]{2}{*}{ WAKTU } & \multicolumn{6}{|c|}{ JUMLAH PANGGILAN } & \multirow{2}{*}{$\begin{array}{l}\text { Rata-rata } \\
\text { Lama } \\
\text { panggilan } \\
\text { (Menit) }\end{array}$} & \multirow[b]{2}{*}{ SNR } \\
\hline & $\mathbf{S}$ & $\mathbf{S}$ & $\mathbf{R}$ & $\mathbf{K}$ & $\mathbf{J}$ & $\mathbf{S}$ & & \\
\hline $07.00-09.00$ & 9 & 16 & 18 & 29 & 17 & 6 & \pm 10 & 24 \\
\hline $09.00-11.00$ & 7 & 21 & 10 & 31 & 2 & 5 & \pm 10 & 25 \\
\hline $11.00-13.00$ & 10 & 23 & 9 & 15 & 5 & 6 & \pm 10 & 26 \\
\hline $13.00-15.00$ & 4 & 28 & 15 & 21 & 14 & 1 & \pm 10 & 24 \\
\hline $15.00-17.00$ & 9 & 14 & 21 & 10 & 6 & 2 & \pm 10 & 28 \\
\hline $17.00-19.00$ & 14 & 10 & 2 & 5 & 8 & 2 & \pm 10 & 30 \\
\hline $19.00-21.00$ & 17 & 23 & 12 & 6 & 14 & 0 & \pm 10 & 25 \\
\hline
\end{tabular}

Analisis hasil pengamatan kondisi trafik jaringan speedy selama sebulan sesuai tabel 1 samapai dengan tabel 4 di atas secara grafik dapat digambarkan perubahannya sebagai berikut :

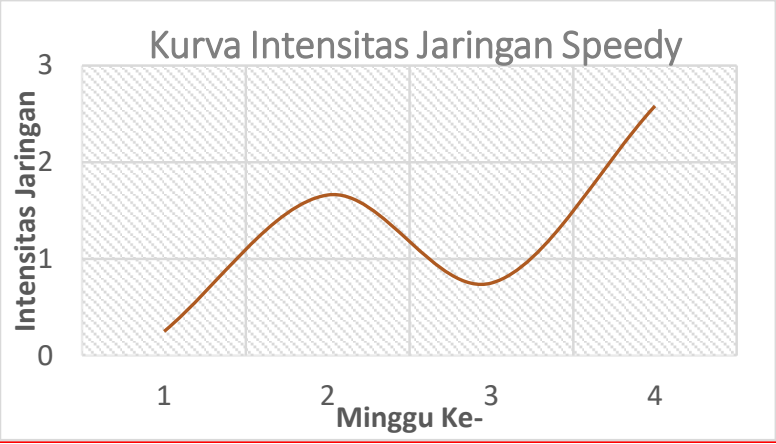

Gambar 3. Perubahan Intensitas Jaringan Speedy selama 1 bulan

Sedangkan intensitas trafik saat jam sibuk dapat diukur melalui pendekatan Bouncing Busy Hour disesuaikan dengan kondisi lapangan. Adapun hasil perhitungan dan digambar seperti yang tertera pada grafik berikut ini

1. Minggu ke-1 (jumlah panggilan maksimal terjadi pada hari jumat sebesar 14 panggilan):

$$
\text { Trafik Rata }- \text { rata Jam Sibuk }=\frac{14}{6}
$$$$
=2,33
$$

2. Minggu ke-2 (jumlah panggilan maksimal terjadi pada hari jumat sebesar 48 panggilan):

$$
\begin{gathered}
\text { Trafik Rata - rata Jam Sibuk } \\
=\frac{48}{6}=8
\end{gathered}
$$

3. Minggu ke-3 (jumlah panggilan maksimal terjadi pada hari jumat sebesar 35 panggilan) :

$$
\text { Trafik Rata }- \text { rata Jam Sibuk }=\frac{35}{6}
$$$$
=5,83
$$ 
4. Minggu ke-4 (jumlah panggilan maksimal terjadi pada hari selasa sebesar 135 panggilan):

$$
\begin{array}{r}
\text { Trafik Rata - rata Jam Sibuk } \\
=\frac{135}{6}=22,5
\end{array}
$$

Secara grafik dapat digambar sebagai berikut:

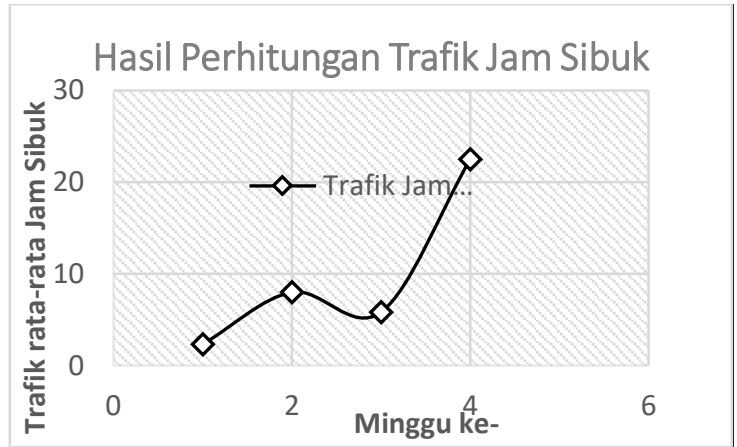

Gambar 4. Intensitas Trafik saat Jam Sibuk

\subsection{Perhitungan Grade of Service (GOS) Trafik Jaringan Speedy}

GOS dihitung untuk memperkirakan probabilitas panggilan ditolak pada keadaan jam sibuk selama 1 bulan berdasarkan intensitas panggilan tertinggi dimana tahapan perhitungannya digambarkan sebagai berikut:

1. Intensitas (A) tertinggi $=2,58$

2. Jumlah minggu $(n)=4$

$$
\begin{gathered}
\text { GOS }=\frac{(2,58)^{4} / 4 !}{1+2,58+\left(\frac{2,58^{2}}{2 !}\right)+\left(\frac{2,58^{3}}{3 !}\right)+\left(\frac{2,58^{4}}{4 !}\right)} \\
=\mathbf{1 5 , 9} \%
\end{gathered}
$$

Sehingga jumlah panggilan yang ditolak (blocking call) oleh sistem sebanyak:

$$
\begin{aligned}
\text { Blocking Call } & =15,9 \% \times 135 \\
& = \pm 21 \text { panggilan }
\end{aligned}
$$

\subsection{Perkiraan Perbaikan Kapasitas Jaringan Speedy}

Identifikasi perbaikan sistem jaringan speedy ini adalah memperkirakan bandwidth dan kapasitas tambahan dari yang sudah ada bagi jaringan ketika intensitas dan trafik rata-rata mencapai keadaan maksimal. Adapun perhitungannya dilakukan menggunakan pendekatan formulasi shannon sehingga didapat perhitungannya merujuk pada spesifikasi data yang diasumsikan sudah tersetting dalam jaringan speedy:

1. Kapasitas (C) awal : 1 Mbps

2. Bandwidth $\left(\mathrm{B}_{\mathrm{W}}\right)$ awal $: 1 \mathrm{MHz}$

3. SNR maksimal $: 42$

Dengan mengambil nilai SNR tertinggi ketika intensitas jumlah panggilan selama satu bulan, maka diperoleh perkiraan kebutuhan kapasitas jaringan sebesar:

$C=1 \mathrm{MHz} \times \log _{2}(43)=5,33 \mathrm{Mbps}$

Sehingga perkiraan penambahan kapasitas jaringan untuk memperbaiki dan memaksimalkan jaringan speedy dari kapasitas awal sebesar 5,33 Mbps. Hal menunjukan bahwa untuk menjaga agar jaringan tidak mengalami gangguan yang besar maka ada penambahan kapasitas dibutuhkan sekitar 4,33 Mbps untuk mencapai kapasitas jaringan sebesar 5,33 Mbps sesuai perhitungan

\section{KESIMPULAN}

Model perbaikan jaringan speedy saat trafik jam sibuk diperkirakan membutuhkan kenaikan kapasitas jaringannya sebesar 5,33 Mbps dari kapasitas awalnya sebesar 1 Mbps sedangkan probabilitas penolakan panggilan saat jam sibuk diperoleh sebesar 15,9 \% dengan jumlah pelanggan yang tertolak berdasarkan nilai Grade of service sebanyak \pm 21 orang dari total panggilan 135 panggilan yang masuk saat jam sibuk.

\section{DAFTAR PUSTAKA}

[1] D. Bear, Principle of Telecommunication Traffic Engineering, 3rd edition, Peter Peregrinus, 1988

[2] J. E. Flood, Telecommunication Switching, Traffic and Network, Prentice-Hall, 1995

[3] ITU-D (Study Group D), Teletraffic Engineering, Geneva December 2003

[4] Helmy Fitriawan (2008), Teknologi Digital Subscriber Line sebagai salah satu solusi 
komunikasi data kecepatan tinggi, http://onno.vlsm.org/v11/ref-ind-

[5] OBENGWARE (2007), Setup ADSL Telkom Speed,www.obengware.comladsllsetupadslt elkomspeedy.html.
[6] Sri P. Rahayu, Instalasi dan Set up Modem ADSL, 2006 